\title{
Conceiving Function Transformations in Different Representations: Middle School Students Working with Technology
}

\author{
Ahlam Anabousy ${ }^{1}$, Wajeeh Daher ${ }^{2}$, Nimer Baya'a ${ }^{3}$, Mohammad Abu-Naja ${ }^{4}$ \\ ${ }^{1}$ Al-Qasemi Academic College of Eduction \\ ${ }^{2}$ Al-Qasemi Academic College of Eduction \& An-Najah National University \\ ${ }^{3}$ Al-Qasemi Academic College of Eduction \\ ${ }^{4}$ Al-Qasemi Academic College of Eduction \& Kay Academic College of Eduction
}

\begin{abstract}
The current research describes an experiment in which we tried to facilitate nineteen grade 9 students' learning of function transformations through solving exploration activities by using Geogebra. Doing so, we wanted to characterize the participating students' understanding of the different themes associated with the topic. The research results show that working with Geogebra, grade 9 students generally succeeded to work with function transformations in their algebraic and graphic representations. This success is attributed to the properties of the technological tool, where its interface includes both the graphic and the algebraic representations. At the same time, the activities being explorative also contributed to students' success in this topic. Furthermore, the participating students had some difficulties working verbally with function transformations, especially when the reflection transformation was involved. This result points at the need of students' involvement with three representations to conceive deeply and accurately the different themes of the topic, namely, the algebraic, the graphic and the verbal representations.
\end{abstract}

Keywords: Function Transformations, Students' Conceptions, Middle School, Mathematical Representations, Technology

\section{INTRODUCTION}

Various educational institutions and researchers emphasized the importance of the 'function transformations' topic to the learners of mathematics (National Council of Teachers of Mathematics (NCTM), 1989, 2000; National Mathematics Advisory Panel, 2008). Doing so, they emphasized the benefits of this topic to students' learning of mathematics. For example, the NCTM (1989) argues that using an approach that highlights the connections between geometry and algebra provides a structure through which students can explore properties of functions. Furthermore, the NCTM (2000) and NCTM (1989) pointed at the importance of utilizing transformations in learning functions and in other mathematical situations. The NCTM (1989), for example, encouraged the use of transformational approach to graphing functions rather than graphing using a table of values, while the NCTM (2000) emphasized relationships and the analysis of change in the study of functions. Researchers also reported students' understanding and difficulties with the topic. For example, the National Mathematics Advisory Panel (2008) reported that many students do not understand the procedures for transforming functions or why they are 
done the way they are, which could be a result of the subject being taught by memorizing and applying rules without understanding the underlying concepts (Faulkenberry, 2011). This importance of the topic of function transformations to the learners of mathematics and their difficulty in learning it encourages using alternative methods in its teaching and learning. So, different methods are suggested today to teach the topic of function transformations, for example modern dance (Bingham, 2007), toothpicks (PBS MATHLINE, 2013), and technology (Consciência \& Oliveira, 2011). We decided to use technology, specifically Geogebra, as a tool in the hands of grade nine students, in order to help them investigate the different concepts of function transformations. We chose Geogebra for three reasons. First, it's a free program. Second, it can be presented in any language you choose, and third, it can be utilized for building mathematical objects, in our case, transformations. We intended from the beginning to engage our students with transformations where they build with the help of technology these transformations, so that the knowledge embedded in the construction process helps them understand the topic's various themes as the original function, direction of a translation, magnitude of a transformation, and the reflection axis.

\section{Literature Review}

Researchers described students' understanding of function transformations together with the description of their difficulties doing so (Eisenberg \& Dreyfus, 1994; Kimani \& Masingila, 2006; Lage \& Gaisman, 2006), where the researches' results showed students' difficulties in dealing with function transformations and tried to explain the sources of these difficulties. One the first studies on this topic is that of Eisenberg and Dreyfus (1994) who were interested in how computer technology could assist students in grasping the conception of transformations. Specifically, they examined how the visual representation of functions enabled by technology helped high school students combine between visual and algebraic thinking in the context of function transformations. After six lessons on function transformations using computer software, the students' visual processing increased, as well as their success rate of performing transformations on functions whose representation they had internalized (quadratics), but even after the experiment, the students were far less successful in dealing with higher order polynomials. Moreover, Eisenberg and Dreyfus observed that an object conception of function might be a condition to the effective understanding of function transformations.

Kimani and Masingila (2006) were interested not only in students' learning of transformations but also in students' flexibility among three concepts associated with functions: function transformations, function inverse, function composition. To investigate this issue, Kimani and Masingila examined through task-based interviews eight university calculus students' flexibility among the three concepts. Their study did not show strong evidence that the participants had flexibility in function representation or function view. Furthermore, the findings pointed to a univalent and sometimes heavy dependence on the algebraic representation of a function. In addition, the participants exhibited a strong dependence on a graphing calculator to respond to questions involving function transformations, where they mostly used a guess and check approach with the help of a graphing calculator.

Another study which showed the problematic treatment of function transformations by university students is that of Lage and Gaisman (2006). They interviewed university students while solving problems involving transformations of functions. The results showed that few students could work confidently with transformation problems, where their work demonstrated that they had not interiorized the effects of transformations on functions when it was needed to think in terms of co-variation of the dependent and independent variables of the function. Specifically, students had troubles when they had to identify which transformation had been applied to a particular basic function. When a transformation was given, they had problems finding its properties. All these difficulties were more apparent when the representation used in the question was graphical. 
Few researchers attempted to study students' learning of function stretching. One such a study is that of Sever and Yerushalmy (2007) who described the first attempts of two calculus students to understand the concept of stretching of functions using technological tools, where each of the students was engaged in interpreting dynamic graphs in order to deal with graph stretching in various situations. The authors emphasized the influence of technology on students' learning, saying that "the tool aroused an on-line sensory stimulus through which they could act in a tangible and concrete way on the abstract functions" (p. 1518).

As mentioned above, researchers described students' difficulties with the learning of function transformations together with their description of their understanding of this topic. One of the most mentioned students' difficulties with function transformations is the horizontal translation (Baker, Hemenway \& Trigueros, 2000; Borba \& Confrey, 1996; Eisenberg \& Dreyfus, 1994; Zazkis, Liljedahl, \& Gadowsky, 2003), where different explanations were given for this difficulty. For example, Eisenberg and Dreyfus (1994) suggested that "there is much more involved in visually processing the transformation of $\mathrm{f}(\mathrm{x})$ to $\mathrm{f}(\mathrm{x}+\mathrm{k})$ than in visually processing the transformation of $\mathrm{f}$ to $\mathrm{f}(\mathrm{x})+\mathrm{k}$ " (p. 58). Furthermore, Baker, Hemenway, and Trigueros (2000) argued that "vertical transformations are actions performed directly on the basic functions, while horizontal transformations consist of actions that are performed on the independent variable of the function and further action is needed on the object resulting from the first action to get the result of the transformation" (p. 47). Moreover, Zazkis, Liljedahl and Gadowsky (2003) confirmed that the horizontal translation is counterintuitive for them, and, at the same time, inconsistent with students' expectations. Students' difficulties with the concept of function transformation in general were related to their difficulties with the concept of function and its themes (Baker, Hemenway \& Trigueros, 2000; Lage \& Gaisman, 2006).

The current research also wants to describe students' understanding and difficulties in learning function transformations, but it does so when students learn with Geogebra, a new technological tool that assists students in building and investigating the mathematical objects that they learn.

\section{Research Rationale and Goals}

Lage and Gaisman (2006) pointed at the need for research on students' understanding of function transformations, saying that research on students' understanding of this topic is important for three reasons: it is a topic in many pre-calculus courses, it provides an opportunity to analyze students' ideas on functions and variables, including their use of different representations of function, and the research could be used as a guide for the design of teaching materials and strategies that foster students' understanding of both functions and their transformations. The need and reasons pointed at by Lage and Gaisman (ibid), and which could be categorized as theoretical and practical, were behind our intent to study middle school students' understanding of function transformations with the help of technology, and specifically to see if technology, in our case Geogebra, helps these students study transformation on absolute value, cubic and quartic functions. Our choice of middle school students and not high school students or college students comes from our expectation that Geogebra which is a tool for mathematical constructions and investigations can facilitate students' understanding of transformations on absolute value, cubic and quartic functions.

We thought that considering the different themes in each representation of function transformation would help us analyze students' conceptions of these transformations, for students' conceptions of mathematical entities are related to their conceptions of the different themes of the entity. Furthermore, considering these themes helps us arrive at the source of students' difficulties in function transformations. 


\section{Research Question}

How do middle school students conceive function transformations in the different representations: Algebraic, graphic and verbal, in a technological interactive, visual and dynamic mathematics environment as Geogebra?

What activity characteristics and teaching models in the Geogebra environment could improve students' conception of function transformations in the different representations: Algebraic, graphic and verbal?

\section{METHOD}

\section{Research Context}

The research was conducted in a middle school, specifically with grade 9 advanced students. The function transformations' unit was taught by the first author using Geogebra, which is a relatively new technological tool for teaching and learning of several mathematical topics. The unit was composed of five lessons, where each lesson consisted of 90 minutes. The first lesson reviewed the use of transformation in real life contexts, as well as the main characteristics of the three non-basic functions: $y=|x|, y=x^{4}$ and $y=x^{3}$. The second and third lessons treated the horizontal and the vertical translations respectively. The fourth lesson treated the reflection transformation, while the fifth lesson treated the stretch and compression transformations. Carrying out the transformation activities, the students were asked to describe the relations between the three representations of the transformations, specifically when the algebraic rule of a function was given or when the graph of a function was given. Furthermore, during performing the activities, the teacher worked as a facilitator of students' learning, directing them and requesting them to justify their answers. All the activities were following the exploration strategy, i.e. designed to encourage the students discover by themselves the properties of the transformations, as well as the relations between their themes, with the help of technology, in our case Geogebra. The emphasis of students' work was on the algebraic and graphical representations of functions. They investigated by themselves the transformation topic by answering questions that requested the students to (1) conjecture regarding a phenomenon related to one representation of a transformation, (2) explore this phenomenon through working with GeoGebra, (3) conclude appropriate mathematical relations for the specific case in the phenomenon, and (4) generalize the relation for every function.

The students were engaged individually, each one with a computer, in the different tasks, and, upon finishing each task, they presented their solutions at the teacher's computer that was connected to internet and overhead projector.

\section{Participants}

The participants were 19 advanced grade 9 students who had different individual abilities in mathematics. The decision to work with excellent students was taken due to previous researches' results regarding the difficulties that students confront when they learn transformations, even when the functions are basic ones like the quadratic functions.

\section{Data Collection Tools}

The data was collected from students' answers on two questions after the experiment. The questions evaluated students' recognition of function transformations, where in part (a) of the first question the students were given three algebraic rules of functions and asked to draw each function using transformations performed on the original one, while in part (b) the students were asked to write verbally the transformations related to the same three functions. These functions were: (a) $f(x)=-(x-4)^{4+7}$, (b) $f(x)=4|x-3|+8$, and (c) $f(x)=-(x+3)^{3+4}$. 
In part (a) of the second question, the students were given three graphs of functions and asked to write the rule of each function using transformation performed on the original one, while in part (b) of the second question the students were asked to write the transformations performed on the same three functions verbally. The three graphs given in the post experiment task are described in Figure 1.

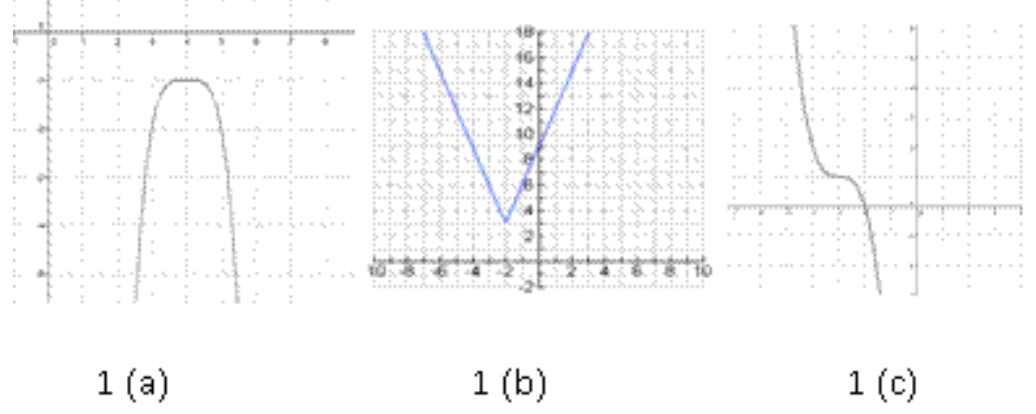

Figure 1. The three given graphs in the second task

In both questions, the three functions were ones that the students had worked before with, where the functions were a quartic function, an absolute function and a cubic function.

\section{Analysis of the Data}

To analyze the collected data we used deductive content analysis, where we performed constant comparisons between the units of gathered data (verbal sentences, graphs, algebraic rules or a combination of them) in order to decompose them into the different themes of the three representations of function transformations.

\section{FINDINGS}

As described above, students, in the first question, were given three algebraic rules of functions and required to draw each function using transformation performed on the original one, as well as to write these transformations verbally. So the first question involved the recognition of graphical and verbal meanings of algebraic operations in terms of transformations, when the transformations should be performed on the original function.

\section{Recognition of the Graphical Meanings of Algebraic Operations in Terms of Transformations}

The following mathematical actions are involved in drawing a function using transformations on the original one: recognizing the original function, recognizing the graphical meanings of the following algebraic operations: adding a positive/negative number to $\mathrm{x}$, adding a positive/negative number to $\mathrm{y}$, multiplying a function with a number, and multiplying a function with $(-1)$.

When drawing the function $f(x)=-(x-4)^{4}+7$, all the nineteen students knew the graphical meanings of the algebraic actions in terms of transformations done on the original function $\mathrm{y}=\mathrm{x}^{4}$, but generally the students drew the resulting function only approximately and in varied extent of accurateness. Some of the students' graphs are shown below in Figure 2. 


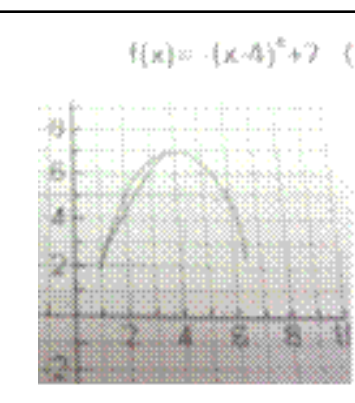

$2 \mathrm{a}$

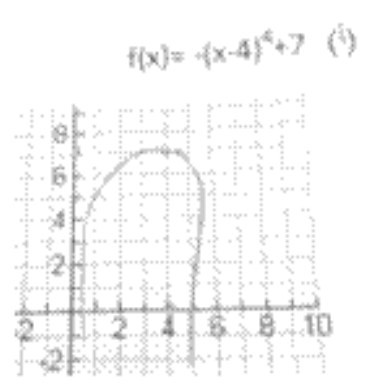

$2 b$

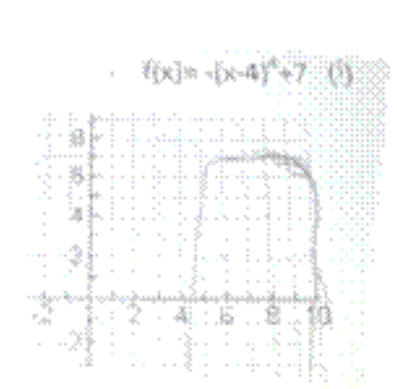

$2 \mathrm{c}$

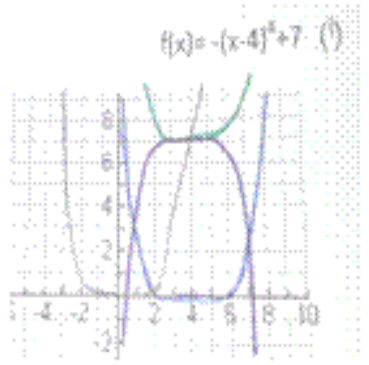

$2 \mathrm{~d}$

Figure 2. Students' drawings in the case of the function $f(x)=-(x-4)^{4}+7$

It could be seen that the students preferred to draw the resulting function, but not to draw manually and graphically the transformations performed on the original function (i.e. they drew the transformations virtually). Only three students showed the transformations as in the case of the student who drew graph $2 \mathrm{~d}$, while the rest (16 students) drew just the resulting function.

Drawing the function $f(x)=4|x-3|+8$, seventeen students knew the graphical meanings of the algebraic actions in terms of transformations done on the original function $\mathrm{f}(\mathrm{x})=|\mathrm{x}|$, while one did not know these meanings and one did not answer the question. Some of the students' graphs are shown below in Figure 3 when they knew the graphical meanings.

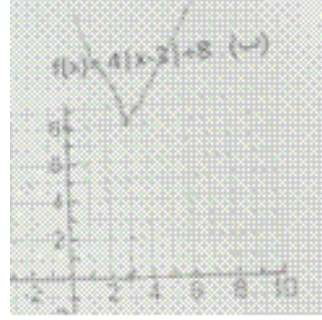

$3 a$

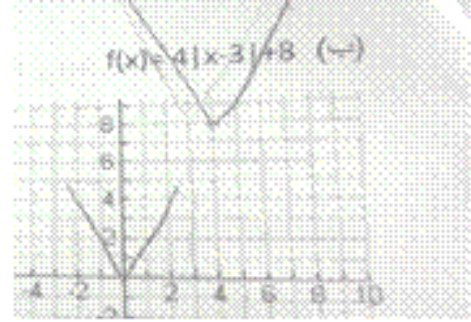

$3 b$

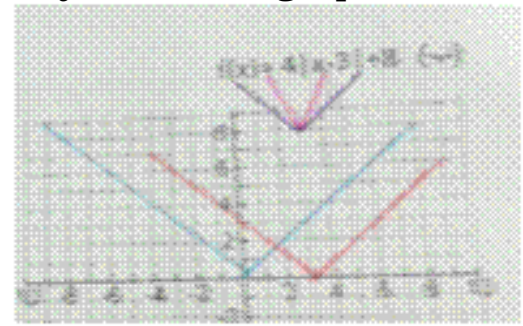

$3 \mathrm{c}$

Figure 3. students' drawings in the case of the function $f(x)=4|x-3|+8$

In this case the students had three ways of arriving at the required function through transformations: twelve students imagined the original function and performed virtually the transformations, as in case $3 \mathrm{a}$, three students drew the original function, performing virtually the transformations and drawing the resulting function (the required one), as in the case of $3 \mathrm{~b}$, and two students drew the original function, performing manually and graphically the transformations, and drawing the resulting function, as in the case of 3c.

The student who did not answer the question drew only the original function without performing any transformations on it, as if he did not know the graphical meanings of the algebraic operations in terms of transformations. The student's graph is shown in Figure 4.

$$
f(x)=4|+3|-8
$$

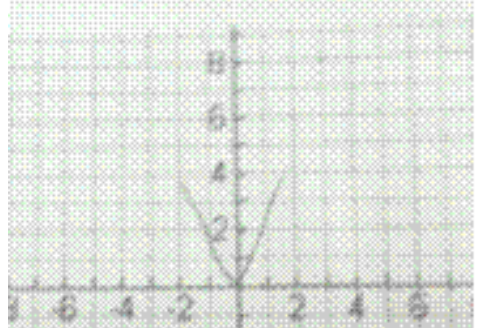

Figure 4. Student's graph when not recognizing the graphical meaning of algebraic operations in terms of transformations - the case of the function $\mathrm{f}(\mathrm{x})=4|\mathrm{x}-3|+8$ 
Drawing the function $f(x)=-2(x+3)^{3}+4$, fourteen students knew the graphical meanings of the algebraic actions in terms of transformations done on the original function $\mathrm{f}(\mathrm{x})=\mathrm{x}^{3}$, while three knew only part of these meanings and two did not answer the question.

Some of the students' graphs are shown below in Figure 5 when they knew the graphical meanings.

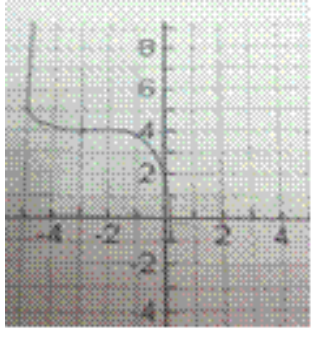

$5 a$

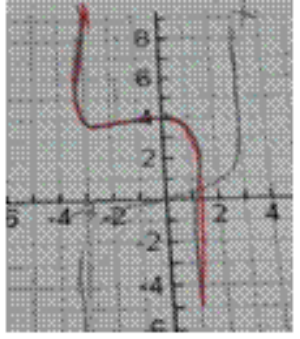

$5 b$

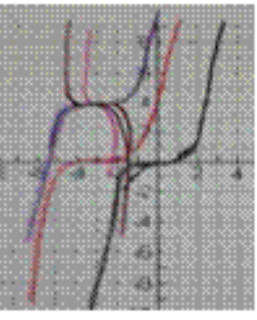

$5 \mathrm{c}$

Figure 5. Students' drawings in the case of the function $f(x)=-2(x+3)^{3}+4$

In this case too, the students had three ways to arrive at the required function through transformations performed on the original function. Eleven students imagined the original function and performed virtually the transformations, as in case 5a, two students drew the original function, performing virtually the transformations and drawing the resulting function, as in the case of $5 \mathrm{~b}$, and one student drew the original function, performing manually and graphically the transformations, and drawing the resulting function, as in the case of $5 c$.

As described above, three students knew only part of the graphical meanings of algebraic operations in terms of transformations. One of the students did not recognize the graphical meaning of multiplying with (-1), as well as of adding a number to $\mathrm{x}$. this student's graph is in Figure 6(a), the second student did not recognize the graphical meaning of multiplying with $(-1)$, as in Figure $6(\mathrm{~b})$. The third student knew only the graphical meaning of multiplying with $(-1)$, but did not know the graphical meanings of adding a number to $\mathrm{x}$ or adding a number to y, as in Figure 6(c).

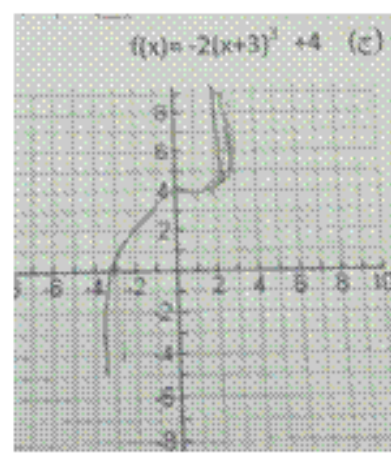

$6(a)$

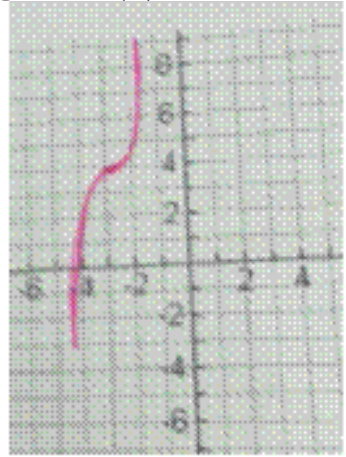

6 (b)

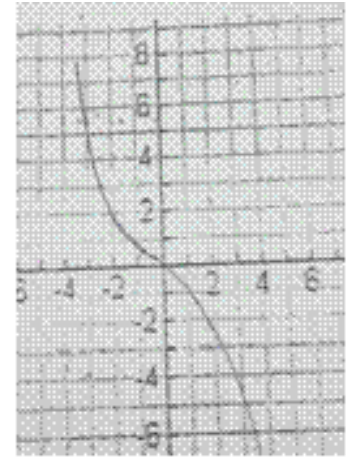

6(c)

Figure 6. Graphs of students who recognized only part of the graphical meanings of algebraic operations in terms of transformations

Table (1) shows the frequency of students' drawings in terms of the recognition of transformations (associated with algebraic operations) performed on the rule of the original function to get the graph of the given function. 
Table 1. Frequency of students' graphs in terms of their recognition of transformations done on the algebraic rule of an original function to arrive at the graph of the given function $(\mathrm{N}=19)$

\begin{tabular}{|c|c|c|c|}
\hline Algebraic rule & $\begin{array}{l}\text { Recognizing the } \\
\text { graph of the original } \\
\text { function and } \\
\text { recognizing the } \\
\text { graphical meanings } \\
\text { of the different } \\
\text { algebraic operations }\end{array}$ & $\begin{array}{l}\text { Recognizing the } \\
\text { graph of the original } \\
\text { function, but not } \\
\text { knowing the graphical } \\
\text { meaning of at least } \\
\text { one of the different } \\
\text { algebraic operations }\end{array}$ & $\begin{array}{l}\text { Not drawing a } \\
\text { graph }\end{array}$ \\
\hline$f(x)=-(x-4)^{4}+7$ & 19 & & \\
\hline$f(x)=4|x-3|+8$ & 17 & 1 & 1 \\
\hline$f(x)=-2(x+3)^{3}+$ & 15 & 2 & 2 \\
\hline
\end{tabular}

The frequency of students' answers, in terms of recognition of graphical meanings of algebraic operations performed on the original function to get the graph of the given function is shown in Figure 7.

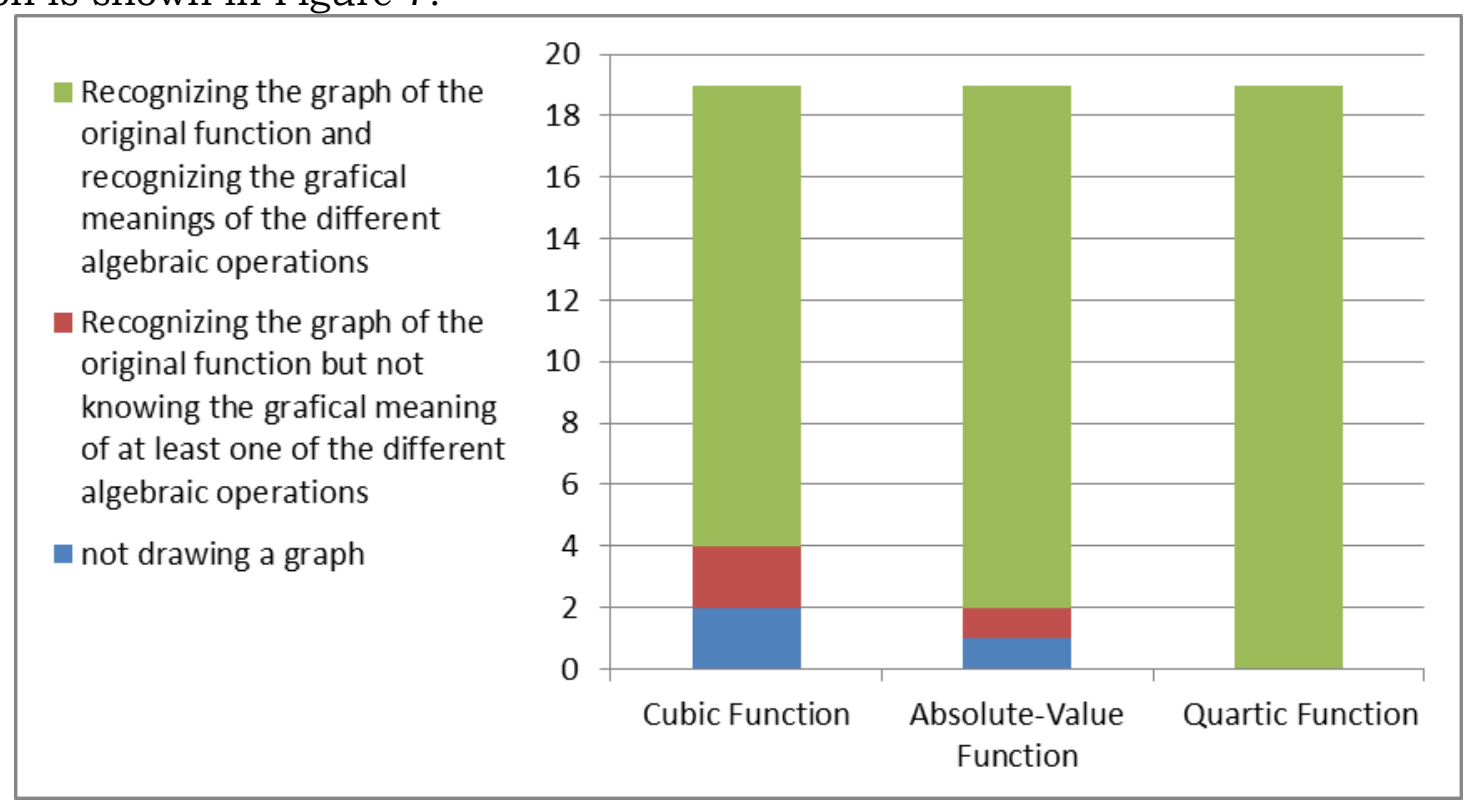

Figure 7. Frequency of students' answers, in terms of recognizing the graphical meanings of algebraic operations in terms of transformations

In the second part of the first task the students were asked to describe verbally the transformations performed on the original function to get the given one. Below is a description of students' recognition of the verbal meanings involved.

\section{Recognition of Verbal Meanings of Algebraic Operations in Terms of Transformations}

The following mathematical actions are involved in describing verbally a function in terms of the transformations performed on the original one: recognizing the original function, recognizing the verbal meanings of the following algebraic operations: adding a positive/negative number to $\mathrm{x}$, adding a positive/negative number to $\mathrm{y}$, multiplying a function with a number, multiplying a function with -1 , the order of the transformations. Also involved are recognizing the reflection axis when a reflection transformation is involved.

Describing verbally the transformations performed on the rule of the original function in the case of each one of the three given rules, the students behaved in one of three ways: (1) 
expressing verbally all the transformations (translations, reflections and compression) and themes (direction of a translation, magnitude of a translation or a compression, the original function and the reflection axis) associated with the algebraic actions done on the original function to get the given one, (2) expressing verbally all the transformation but not all the themes associated with the algebraic actions done on the original function to get the given one, and (3) expressing verbally all the themes but not all the transformations associated with the algebraic actions done on the original function to get the given one.

Table (2) shows the frequency of students' verbal expressions in terms of their recognition of transformations performed on the algebraic rule of the original function to get the graph of the given one.

Table 2. Frequency of students' verbal expressions in terms of their recognition of transformations done on the algebraic rule of the original function to arrive at the graph of a given one

\begin{tabular}{|c|c|c|c|}
\hline Algebraic rule & $\begin{array}{l}\text { Expressing } \\
\text { verbally all the } \\
\text { transformations } \\
\text { and themes }\end{array}$ & $\begin{array}{l}\text { Expressing verbally } \\
\text { all the transformations } \\
\text { but not all the themes }\end{array}$ & $\begin{array}{l}\text { Expressing verbally } \\
\text { all the themes but not } \\
\text { all the transformation }\end{array}$ \\
\hline$f(x)=-(x-4)^{4}+7$ & 2 students & $\begin{array}{l}16 \text { students forgot } \\
\text { to mention the } \\
\text { reflection axis and } \\
\text { missed the accurate } \\
\text { order of the } \\
\text { transformations }\end{array}$ & $\begin{array}{l}1 \text { student did not } \\
\text { express the reflection } \\
\text { transformation: in place } \\
\text { of it, the student } \\
\text { mentioned } \\
\text { compression }\end{array}$ \\
\hline$f(x)=4|x-3|+8$ & 4 students & $\begin{array}{l}14 \text { students did not } \\
\text { express the reflection } \\
\text { axis and missed the } \\
\text { accurate order of the } \\
\text { transformations } \\
1 \text { student did not } \\
\text { express the original } \\
\text { function }\end{array}$ & \\
\hline$f(x)=-2(x+3)^{3}+4$ & 6 students & $\begin{array}{l}11 \text { students did not } \\
\text { express the reflection } \\
\text { axis and missed the } \\
\text { accurate order of the } \\
\text { transformations. }\end{array}$ & $\begin{array}{l}2 \text { students did not } \\
\text { express the reflection } \\
\text { transformation }\end{array}$ \\
\hline
\end{tabular}

The frequency of students' answers, in terms of recognition of the verbal meanings of function transformations done on the algebraic rule of the original function to arrive at the graph of a given one, is shown in Figure 8.
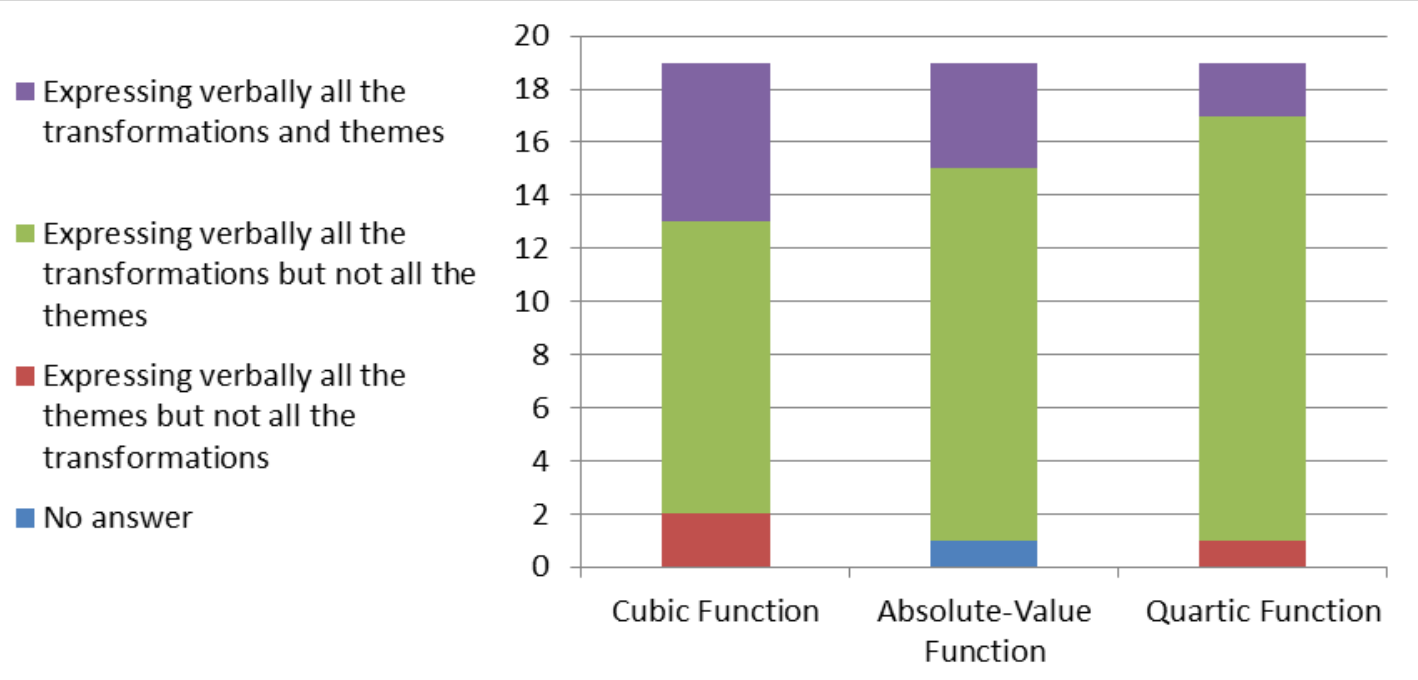

Figure 8. Frequency of students' answers, in terms of in terms of recognition of the verbal meanings of function transformations 
In the first part of the second question, the students were given three graphs of functions and required to write the rule of each function using transformation performed on the graph of the original one, as well as to write these transformations verbally. So, the second question involved the recognition of algebraic and verbal meanings of graphical operations in terms of transformations performed on the graph of the original function.

\section{Recognition of the Algebraic Meanings of Graphical Operations in Terms of Transformations}

The following mathematical actions are involved in writing the rule a function using transformations on the graph of the original one: recognizing the original function, recognizing the algebraic meanings of the following graphical operations: translating a graph horizontally with attention to the direction and magnitude of the translation, translating a graph vertically with attention to the direction and magnitude of the translation, reflecting a graph of a function with attention to the reflection axis, performing expansion or compression on the graph of a function with attention to the magnitude of the expansion or compression.

Writing the rule of a given graph through considering the transformations performed on the graph of the original function of each one of the three given graphs, the students behaved in one of three ways: (1) took into consideration all the appropriate transformations and related themes, (2) took into consideration all the appropriate transformations but not all the appropriate themes, and (3) took into consideration all the appropriate themes but not all the appropriate functions.

Table (3) shows the frequency of students' algebraic behaviors in terms of their recognition of transformations performed on the graph of the original function to get the algebraic rule of the given one.

Table 3. Frequency of students' verbal expressions in terms of their recognition of transformations done on the algebraic rule of the original function to arrive at the algebraic rule of the given one

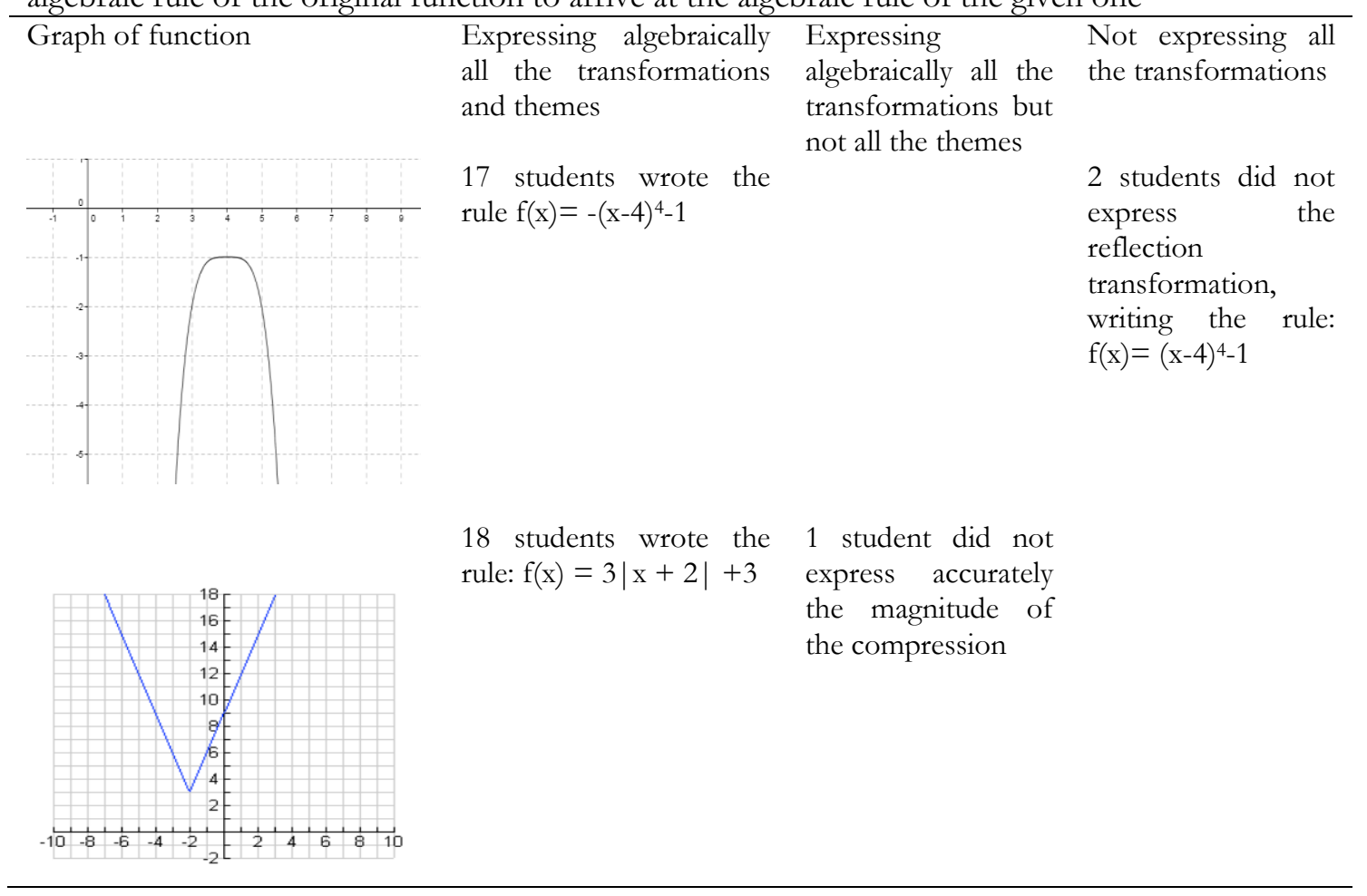




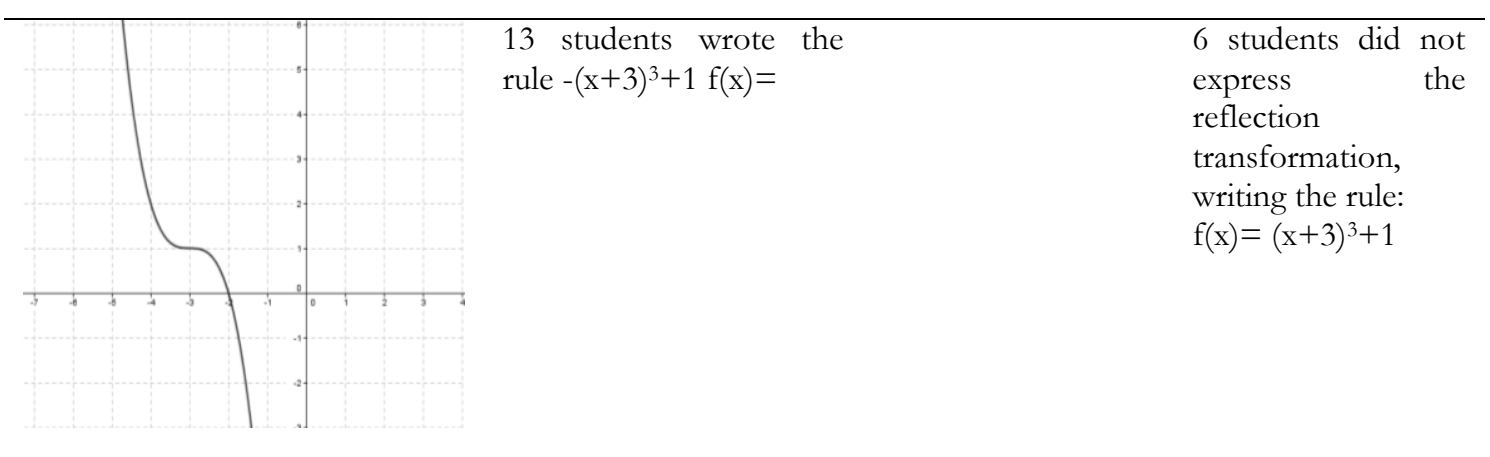

The frequency of students' answers, in terms of correctness and exactness is shown in Figure 9.

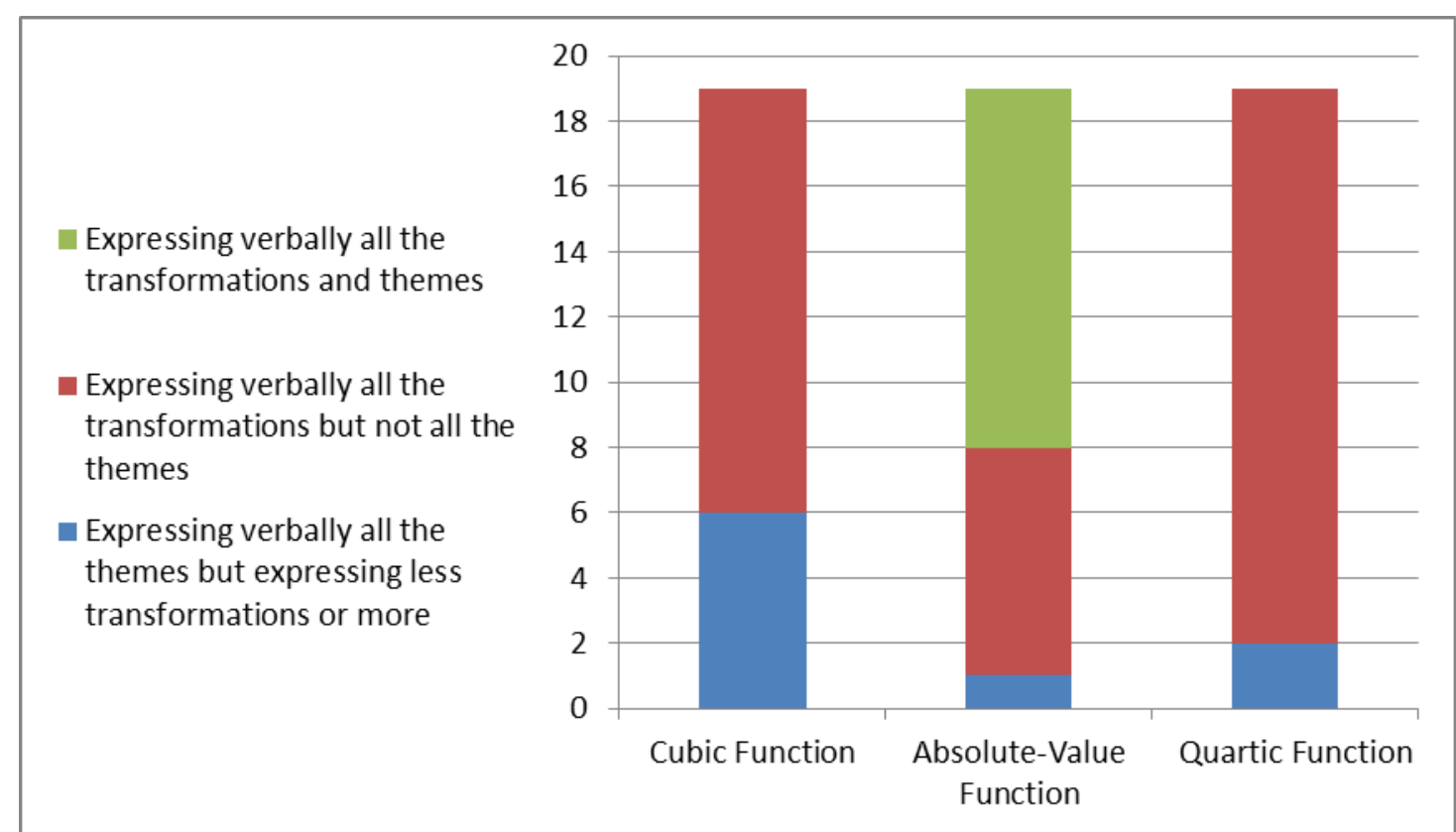

Figure 9. Frequency of students' recognition of transformations and related themes, when performed on the graph of an original function to get a given one

\section{Recognition of the Algebraic Meanings of Graphical Operations in Terms of Function Transformations}

The following mathematical actions are involved in the verbal description of transformations performed on the graph of the original one to get the rule of a given function: recognizing the original function, recognizing the verbal meanings of the following graphical operations: translating a graph horizontally with attention to the direction and magnitude of the translation, translating a graph vertically with attention to the direction and magnitude of the translation, reflecting a graph of a function with attention to the reflection axis, performing expansion or compression on the graph of a function with attention to the magnitude of the expansion or compression, and paying attention to the order of the transformations.

Describing verbally the transformations performed on the graph of the original function of each one of the three given graphs, the students behaved in one of three ways: (1) expressing verbally all the transformations and themes associated with the graphical actions done on the graph of the original function to get the rule of the given one, (2) expressing verbally all the transformation but not all the themes associated with the graphical actions done on the graph of the original function to get the given one, and (3) 
expressing verbally all the themes but not all the transformations associated with the graphical actions done on the graph of the original function to get the given one.

Table (4) shows the frequency of students' verbal expressions in terms of their recognition of transformations performed on the graph of the original function to get the algebraic rule of the given one.

Table 3. Frequency of students' verbal expressions in terms of their recognition of transformations done on the graph of the original function to arrive at the algebraic rule of a given one

Graph of function
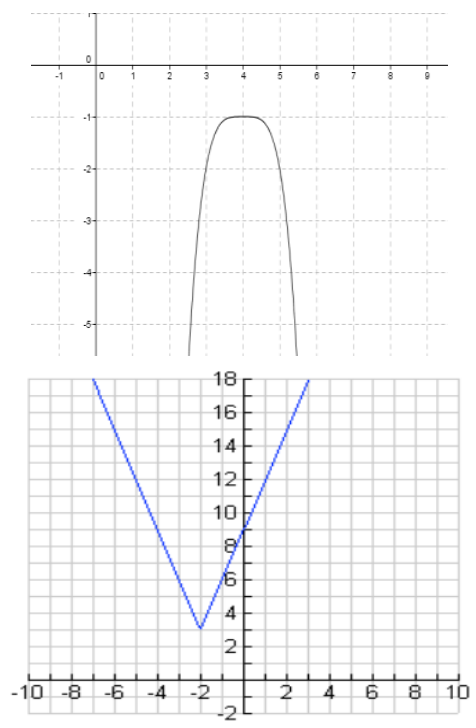

11

Expressing
verbally all the all the transformations
transformations but not all the themes
and themes

17 did not express the reflection axis, where 8 of them did not express the original function too
7 did not express the original function

Expressing verbally
all the themes but
expressing
transformations
more

more

2 did not express the reflection transformation
1 student added a compression transformation which is not needed

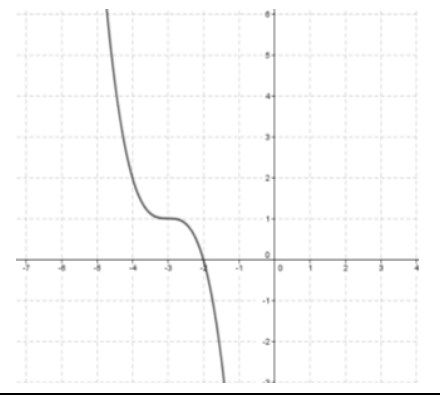

13 did not mention the original function, or the reflection axis too
6 did not express the reflection transformation

The frequency of students' answers, in terms of correctness and exactness is shown in Figure 10. 
즐 Expressing verbally some of the transformations and themes

Expressing verbally all the transformations but not all the themes

츨 Expressing verbally all the transformations and themes

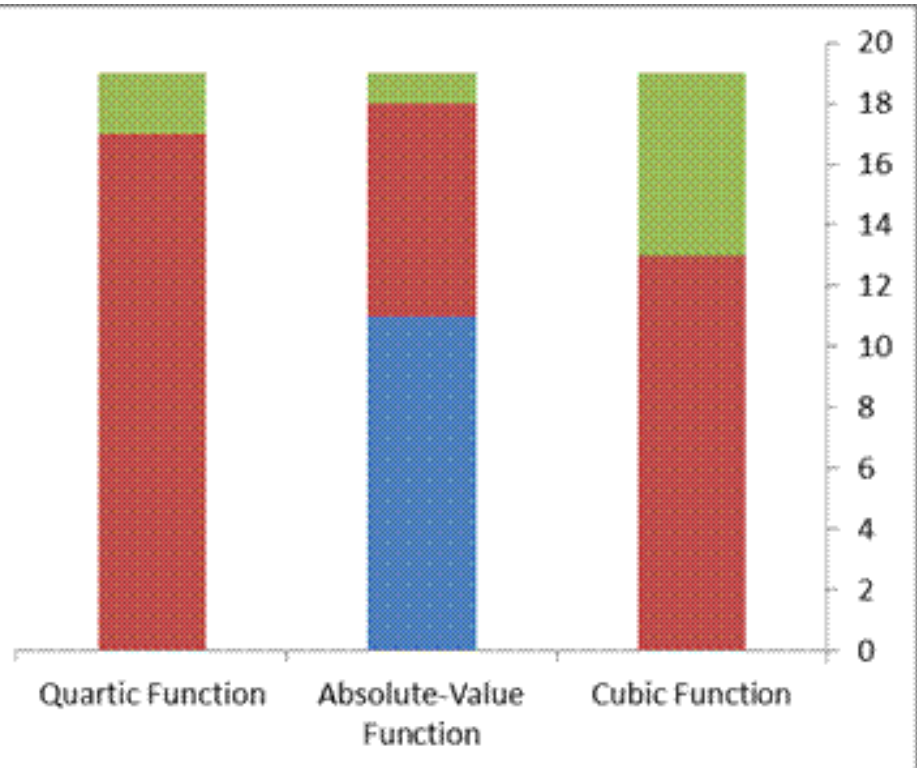

Figure 9: Frequency of students' recognition of transformations and related themes, when performed on the graph of an original function to get a given one

\section{DISCUSSION}

Learning the topic of function transformations is essential for mathematics students because understanding this topic makes it easy to understand other main math topics as functions (Lage \& Gaisman, 2006). Furthermore, students encounter difficulties learning the topic, such as conceiving the horizontal translation (Eisenberg \& Dreyfus, 1994; Zazkis, Liljedahl \& Gadowsky, 2003). In this research we expected that teaching function transformations to middle school students by using technology, specifically Geogebra, would help them conceive better the different themes associated with this topic. We will discuss the current research results by referring to students' recognition of the meanings of mathematical operations in the different representations of function transformations.

The participating students succeeded generally in working with the algebraic and graphical transformations, where this success stems from two reasons: working with a dynamic tool and working with exploration tasks, where they investigated by themselves and gradually the transformation. The type of the activity being explorative is acknowledged in the literature as contributing positively to students' learning (see for example Bishop, 1993; Nunes, 1993). This is also the case with the positive influence of dynamic tools, specifically GeoGebra on students mathematics learning (Diković, 2009; Karadag \& McDougall ،2009a ،2009b).

Regarding the graphical meanings of the algebraic operations, the participating students generally succeeded to recognize the graphical meanings of algebraic operations in terms of transformations in the three familiar functions (cubic, quartic and absolute), but they had relative difficulty when treating the cubic function. This difficulty appeared in students' attempts to perform reflections on the cubic function; probably due to the similarity between the original function and the reflected one (the two parts of the each function are rotationally symmetric). It could be said that students' difficulty, in the case of the cubic function, is attributed to the complexity of mental construction needed to process the reflection of the cubic function. This complexity of mental construction was mentioned by Baker, Hemenway and Trigueros (2000) as lying behind students' difficulty with horizontal transformation. The students had no or little difficulties in recognizing the graphical meanings of algebraic operations in terms of transformations in the case of the absolute and the quartic functions, probably because of their similarity to the quadratic function 
which the students were used to (a reflection axis, extreme points, increasing and decreasing domains).

The participating students generally succeeded to recognize the algebraic meanings of graphical operations in terms of transformations in the three familiar functions (cubic, quartic and absolute). Furthermore, the students had relative difficulty in treating the cubic function. This difficulty appeared specifically in students' attempts to recognize the algebraic meanings of the reflection transformation. As we described above, this difficulty is associated with students' inability to recognize the relation between the cubic function and its reflected one.

It could be claimed that students' relative successful work and moving between the algebraic and graphical representations of function transformations is a result of the availability of both the algebraic and graphic representations in the interface of geogebra (Dikovic, 2009). The relative successful work of the participating students did not continue when the students came to represent verbally the required transformations, for most of them did not succeed in recognizing the verbal meanings of algebraic operations in terms of transformations. Generally, the students encountered difficulties mentioning the reflection axis and its related theme, namely the order of transformations (the non-mentioning of the reflection axis makes it difficult to evaluate the accurateness of the order of transformations). Students' difficulties working verbally with transformations could be due to their inability to transfer their knowledge regarding function transformations in the graphic or the algebraic context to function transformations in the verbal context. This inability to transfer knowledge across representations is reported in previous researches, for example Nguyen and Rebello (2009) reported that students encountered difficulties when attempting to transfer their problem solving skills across problems in different representations. Students' difficulties working verbally with transformations could also be due to the absence of the verbal representation in the Geogebra interface and, at the same time, due to the absence of exploration activities in which students were asked to work with various transformations given verbally in order to investigate the resulting function. Specifically, the previous reasons were behind students' inattention to the reflection axis and the order of the transformations. These explanations are supported by Consciência and Oliveira (2011) who argue that using exploration tasks focusing on one representation of transformations leads to students' difficulties in understanding transformations' concepts, so the emphasis on the verbal representation in the exploration activities would lessen students' difficulties with this representation. In our case, giving students verbal representation of transformations that include reflections of the same function, but with a different reflection axis, would make the students aware of the influence of the axis on the transformed function. The same thing is true regarding the related theme, namely the order of transformations.

More than half of the participating students succeeded to recognize the verbal meanings of graphic operations in the case of the absolute function in terms of transformations. This relative success could be related to the fact that moving from the original absolute function to the given one did not involve performing the reflection transformation (in our case). So, it seems that the students had difficulty with the reflection transformation in general, but this appeared more when the reflection was performed on the cubic function. This students' difficulty was represented in their inability to recognize the verbal meanings of some graphic operations (in terms of transformations) in the case of the quartic function, as well as the cubic function. Specifically, this inability appeared in their non-mentioning of the reflection axis and the original function. students' difficulty with the reflection axis is also mentioned by Lage and Gaisman (2006) who reported students' difficulty with the reflection axis, considering it always to be the x-axis. Moreover, Panaoura, Elia, Stamboulides and Spyrou (2009) found that students encounter difficulties in giving a proper definition for the concept of the reflection axis and resolving tasks involving conversions between diverse modes of its representations. Furthermore, it could be said that students' difficulties here were due to the same reasons mentioned above regarding the difficulties in recognizing the 
verbal meanings of algebraic operations in terms of transformations, i.e. the relatively little involvement of the students with activities dealing with the verbal representation of the transformations, the unavailability of the verbal representation in the interface of the technological tool, and students' inability to transfer their knowledge regarding function transformations in the graphic or the algebraic context to the verbal context.

We have been aware that students behaved differently in performing transformations to arrive at the graph of the transformed function given its rule, where they had three different ways in doing so: drawing just the transformed function, drawing the original function and the transformed one and drawing the transformed function step by step; i.e. drawing the functions resulting from all the transformations involved. Most of the students behaved in the first way, drawing just the transformed function, sometimes drawing marks to help them draw the transformed function accurately. One reason for this behavior could be due to students' mental following of functions' movement in the interface of Geogebra, where they did not require that trace of the function movement to be shown.

\section{CONCLUSION}

Working with Geogebra, students generally succeeded to work with function transformations in their algebraic and graphic representations. This success could be attributed to the properties of the technological tool, as well as to the properties of the given task.

The technological tool helped the students work successfully with transformations because its interface includes both the graphic and the algebraic representations. At the same time, the participating students had some difficulty working verbally with function transformations, especially when the reflection transformation was involved. This could be due to the absence of the verbal representation from GeoGebra interface. On the other hand, the tasks being explorative influenced positively students' understanding of mathematical concepts related to transformations, where this type of tasks is reported in the literature to have such influence on students' learning (see for example Bishop, 1993; Nunes, 1993).

Various researchers were aware of the importance of the visual aspect to the teaching of function transformations, and thus experimented with visual tools in teaching students the topic. Some reported students' difficulties with some aspects of the topic, as the horizontal transformations, even with the presence of technology. We too experimented with using a technological tool, namely Geogebra, to teach the topic. The results of our research point at the need of students' involvement with three representations to conceive deeply and correctly the different themes of the topic, which are associated with the algebraic, the graphic and the verbal representations. Educators have been aware in the last two decades of the importance of the first two representations, but not the third one, namely the verbal representation. It's time to take care of this representation primarily in the activities given to students, but also in the interface of the technological tool. Taking care of the verbal representation would help students overcome their difficulties in paying attention to the reflection axis and its related theme, namely the order of transformations.

\section{REFERENCES}

Baker, B., Hemenway, C., \& Trigueros, M. (2000). On transformations of basic functions. In: H. Chick, K. Stacey, \& J. Vincent (Eds.), Proceedings of the 12th ICMI Study Conference on the Future of the Teaching and Learning of Algebra (Vol. 1, pp. 41-47). University of Melbourne.

Bingham, A. D. (2007). Teaching transformations of functions using modern dance: An experiment pairing a modern dance class with college algebra. Conference on Research in Undergraduate Mathematics Education. February $22-25,2007$, San Diego - Mission Valley, California. http://sigmaa.maa.org/rume/crume2007/ papers/bingham.pdf

Borba, M. C., \& Confrey, J. (1996). A students' construction of transformations of functions in a multirepresentational environment. Educational Studies in Mathematics, 31(3), 319-337. 
Consciência, M. \& Oliveira, H. (2011). Function concept and functions' transformations: The role of the graphic calculator. The Seventh Congress of the European Society for Research in Mathematics Educatio, February 7-13, 2011, Rzeszów, Poland.

Diković, L (2009), Applications GeoGebra into teaching some topics of Mathematics at the College Level, Computer Science and Information Systems , 6(2), 191-203.

Eisenberg, T., \& Dreyfus, T. (1994). On understanding how students learn to visualize function transformations. In: E. Dubinsky, A. Schoenfeld, \& J. Kaput (Eds.), Research in collegiate mathematics education (Vol. 1, pp. 45-68). Providence, RI: American Mathematical Society.

Faulkenberry, E. D. (2011). A conceptual approach to function transformations. In $\mathrm{S}$. L. Reeder (Ed.),Proceedings of the 38th Annual Meeting of the Research Council on Mathematics Learning (pp. 49-55). Cincinnati, OH: RCML.

Karadag, Z., \& McDougall, D. (2009a). Visual explorative approaches to learning mathematics. Atlanta, US: PME-NA.

Karadag, Z. \& McDougall, D. (2009b). Frame Analysis Method: Monitoring Metacognitive Activities. In T. Bastiaens et al. (Eds.), Proceedings of World Conference on ELearning in Corporate, Government, Healthcare, and Higher Education (pp.934939). Chesapeake, VA: AACE.

Kimani, P. M. \& Masingila, J. O. (2006). Calculus students' perceptions of the relationship among the concepts of function transformation, function composition, and function inverse. In A. S., Cortina, J.L., Sáiz, and Méndez, A.(Eds), Proceedings of the 28th annual meeting of the North American Chapter of the International Group for the Psychology of Mathematics Education. Mérida, México: Universidad Pedagógica Nacional, (Vol. 2, pp. 23-30).

Lage, A. E. \& Gaisman, M. T. (2006). An analysis of students' ideas about transformations of functions. In A. S., Cortina, J.L., Sáiz, and Méndez, A.(Eds), Proceedings of the 28th annual meeting of the North American Chapter of the International Group for the Psychology of Mathematics Education. Mérida, México: Universidad Pedagógica Nacional, (Vol. 2, pp. 68-70).
Lyons, M., Lynch, K., Close, S., Sheerin, E. \& Boland, S. (2003). Inside classrooms: the teaching and learning of mathematics in social context. IPA: Dublin.

National Council of Teachers of Mathematics (1989). Curriculum and evaluation standards for school mathematics. Reston, VA: Author.

National Council of Teachers of Mathematics (2000). Principles and standards for school mathematics. Reston, VA: Author.

National Mathematics Advisory Panel. (2008). Foundations for success: The final report of the National Mathematics Advisory Panel. Washington, DC: U.S. Department of Education.

Nguyen, D-H \& Rebello, N. S. (2009). Students' Difficulties in Transfer of Problem Solving Across Representations. Proceedings of the Physics Education Research Conference.

Panaoura, A.; Elia, I.; Stamboulides, N. \& Spyrou, P. (2009). Students' structure for the understanding of the axis of reflective symmetry in mathematics. Acta Didactica Universitatis Comenianae Mathematics, 9, 41-62.

PBS MATHLINE (2013). Toothpicks and Transformations (Quadratic Functions). http://www.pbs.org/teachers/mathline/les sonplans/pdf/hsmp/toothpicks.pdf

Sever, G. \& Yerushalmy, M. (2007).To sense and to visualize functions: The case of graphs' stretching. In P. P. Demetra \& P. George (Eds.), The Fifth Conference of the European Society for Research in Mathematics Education (CERME5). (pp. 1509-1518). Larnaca: Department of Education, University of Cyprus.

Zazkis, R., Liljedahl, P. \& Gadowsky, K. (2003). Conceptions of Function Translation: Obstacles, Intuitions, and Rerouting. Journal of Mathematical Behaviour, 22, 437450 .

\section{$\diamond \diamond \diamond$}

Citation Suggestions :

APA : Anabousy, A., Daher, W., Baya'a, N. \& Abu-Naja, M. (2014). Conceiving function transformations in different representations: middle school students working with technology. Mathematics Education, 9(2), 97-112. 